\title{
Pengembangan Media Pendidikan Kesehatan Flashcard Anemia
}

\author{
Diana Wahyuni ${ }^{1}$, Dahlia Indah Amareta ${ }^{1}$ \\ Jurusan Kesehatan, Politeknik Negeri Jember, Indonesia ${ }^{1}$ \\ e-mail: dianawahyuni882@gmail.com
}

\begin{abstract}
Flashcard is a learning media in the form of a card which its size is $8 \times 12 \mathrm{~cm}$. The pictures on a flashcard are made using photos or existing images and then patched on the flashcard sheets. The purpose of this study was to analyze anemia flashcard as the health education media for female students in SMA Muhammadiyah 3 Jember. Analysis data in this study used qualitative and quantitative descriptive with feasibility tests using a Likert scale. The results of this flashcard media analysis used the Borg and Gall. This type of research used Research and Development research procedures. Subjects in this study are female students, practitioners, material experts, media experts and teachers. The instruments of this study used questionnaire sheets, interviews sheets, FGD guidelines, and assessment questionnaires. The study was conducted at SMA Muhammadiyah 3 Jember in May-July 2018. Data in this research were collected by interview techniques, observation, questionnaires, and FGD. Data analysis in this study used qualitative and quantitative descriptive with feasibility tests that will be developed using a Likert scale. The results of the observation to 51 students obtained that $82 \%$ agreed that flashcard media can help in the process of increasing knowledge about anemia. The average score for all aspects of the contents of flashcards media according to expert media is $92.72 \%$, while according to the material experts is $90 \%$, and according to the teacher is $98.33 \%$. So it can be concluded that the flashcards are "proper" as a learning media.
\end{abstract}

Keywords: anemia, flashcard, learning media.

\section{Pendahuluan}

Anemia merupakan salah satu masalah gizi yang paling sering dijumpai baik pada negara berkembang maupun negara maju. World Health Organization (2011) menyatakan prevalensi anemia pada wanita usia subur sebesar $29 \%$. Prevalensi anemia di Indonesia cukup tinggi, sesuai dengan data Riset Kesehatan Dasar (2007) menyatakan bahwa prevalensi anemia pada perempuan sebesar $11,3 \%$ dan pada remaja putri (usia 15-24 tahun) yaitu sebesar 6,9\%. Data Riskesdas tahun 2013 terjadi peningkatan prevalensi anemia yaitu pada wanita meningkat menjadi $23,9 \%$ dan pada remaja putri menjadi $18,9 \%$, yang berarti terjadi peningkatan prevalensi anemia pada remaja putri menjadi lebih dari $15 \%$, sehingga dapat menjadi indikasi suatu masalah kesehatan di Indonesia (Kemenkes RI, 2013).

Program penanggulangan anemia selama ini hanya terfokus pada ibu hamil, sedangkan remaja putri adalah calon ibu yang harus sehat optimal. Untuk menjadi sumber daya manusia yang tangguh dan berkualitas, diharapkan anemia pada remaja putri dapat dicegah.

Rendahnya pengetahuan siswi tentang informasi kesehatan khususnya tentang anemia, memerlukan adanya inovasi dalam pembelajaran. Salah satu inovasi sebagai upaya dalam meningkatkan pengetahuan tentang anemia adalah dengan menggunakan media flashcard. Flashcard diharapkan menjadi salah satu media untuk menambah pengetahuan siswi tentang kesehatan sehingga mampu meminimalisir kejadian anemia yang dialami remaja putri. Flashcard adalah media pembelajaran dalam bentuk kartu bergambar yang berukuran $8 \times 12 \mathrm{~cm}$. Gambar-gambarnya dibuat menggunakan tangan atau foto, atau memanfaatkan gambar atau foto yang sudah ada yang di tempelkan pada lembaran-lembaran kartu (Susilana dan Riyana, 2009).

Penelitian ini merupakan penelitian yang didahului dengan melakukan observasi di SMA 
Muhammadiyah 3 Jember, dimana dari hasil observasi dan wawancara dengan guru kesiswaan beberapa kali ditemui kondisi siswi yang mengalami tandatanda 5L (lemah, letih, lesu, lalai, lungkai). Media flashcard masih belum umum digunakan sebagai media pembelajaran di dalam sekolah, namun media flashcard memiliki kelebihan daya tarik dari segi karakteristik gambar, desain, warna, dan metode bermain sehingga dapat dijadikan salah satu media pembelajaran tentang anemia. Tujuan penelitian ini adalah untuk mengembangkan media pendidikan kesehatan berupa flashcard anemia pada siswi di SMA Muhammadiyah 3 Jember.

\section{Metode}

Penelitian ini menggunakan prosedur penelitian Research and Development (penelitian dan pengembangan). Subjek penelitian yang digunakan dalam penelitian ini disesuaikan dengan fokus penelitian. Fokus dalam penelitian ini adalah pengembangan media flashcard sebagai media pembelajaran anemia untuk siswi SMA.

\subsection{Metode Pengumpulan Data}

Populasi pada penelitian ini adalah siswi SMA Muhammadiyah 3 Jember, dengan jumlah subjek berjumlah 37 siswi yang diambil dari kelas 1 dan 2 secara purposive sampling. Persetujuan Etik diperoleh dari Komisi Etik Penelitian Kesehatan Politeknik Negeri Jember Nomor 8780/PL17/LL/2018. Penelitian ini dilakukan di SMA Muhammadiyah 3 Jember, dan pelaksanaan penelitian mulai bulan Mei-Juli 2018.

Instrument penelitian ini meliputi lembar kuesioner, lembar wawancara, lembar observasi, lembar panduan FGD(Focus Group Discussion), angket penilaian validator, angket penilaian pelajar, camera handphone, informed consent, dan PSP. Teknik pengumpulan data yang digunakan yaitu wawancara, observasi, kuesioner, dan FGD. FGD dilakukan sebanyak 2 kali yaitu kepada siswi dan validator.

\subsection{Metode Analisis Data}

Pengembangan media ini mengacu pada prosedur metode Borg \& Gall (Tegeh, I. M., Jampel, I. N., \& Pudjawan, K, 2014) dimana terdapat 8 tahap yaitu tahap 1 peneliti menggali informasi awal, tahap 2 desain produk, tahap 3 simulasi produk, tahap 4 revisi, tahap 5 evaluasi produk, tahap 6 revisi, tahap 7 validasi produk, tahap 8 uji lapangan. Penelitian ini menggunakan teknik analisis data yaitu analisis deskriptif kualitatif dan analisis deskriptif kuantitatif.

\section{Hasil Dan Pembahasan}

Hasil wawancara yang dilakukan dengan guru kurikulum dan kesiswaan serta siswi diketahui belum ada informasi tentang kesehatan khususnya tentang anemia pada siswi. Oleh karena itu, materi tambahan ini memerlukan media selain papan tulis dan proyektor. Media diharapkan dapat bersifat inovatif, mudah digunakan, mudah dipahami karena akan digunakan secara mandiri oleh siswi. Dengan adanya media pembelajaran inovatif seperti flashcard ini dapat menambah daya tarik dan mempermudah pembelajaran utamanya mengenai kesehatan seperti tentang anemia. Selain itu, flashcard juga bisa digunakan sebagai media didalam organisasi misalnya ekstra kulikuler PMR yg ada di sekolah tentang kesehatan.

Observasi yang dilakukan di kelas 1 dan 2 SMA Muhammadiyah 3 Jember diketahui bahwa sebagian besar siswi tidak terlihat lemas, akan tetapi terdapat dua siswi mengalami pusing saat pelajaran berlangsung. Siswi terlihat aktif saat belajar dikelas, namun terdapat beberapa siswi yang terlihat sedang bercanda dan tidak mendengarkan guru. Pada saat pembelajaran berlangsung media yang digunakan adalah proyektor dan papan tulis. Informasi terkait kesehatan 
ISSN 2354-5852

e-ISSN 2579-5783

umumnya diberikan di aula, namun pada saat observasi siswi tidak diberikan edukasi atau penyuluhan terkait kesehatan, selain itu juga terdapat kegiatan esktrakurikuler kesehatan di sekolah yaitu Palang Merah Remaja (PMR). Berdasarkan observasi yang dilakukan dapat disimpulkan bahwa siswi memerlukan adanya informasi tentang kesehatan khususnya anemia dengan didukung media pembelajaran yang menarik, mudah digunakan, dan mudah dipahami. penggunaan media dapat merangsang motivasi belajar siswa dan meningkatkan rasa keingintahuan siswa dalam mendapatkan informasi yang disampaikan oleh guru.

Analisis kebutuhan dengan menggunakan kuesioner kepada 51 siswi dapat disimpulkan sebanyak $45 \%$ siswa menjawab ketersediaan media di sekolah kurang memadai, hal ini disebabkan karena di sekolah tidak terdapat media pembelajaran diluar pelajaran sekolah. Pembelajaran mengenai kesehatan hanya disampaikan secara umum yaitu dalam materi IPA dan tidak terdapat media lain yang digunakan dalam proses pembelajaran tersebut selain buku pelajaran.

Analisis kebutuhan terkait topik anemia meliputi definisi anemia, faktor penyebab anemia, tanda dan gejala, dampak anemia, serta penanggulangan anemia. Penelitian yang dilakukan oleh Nugroho, Y.S., Nurkamto, J., and Sulistyowati, H. (2012) menyatakan bahwa dengan menggunakan flashcard dapat meningkatkan kemampuan kosakata siswa karena flashcard dapat menarik perhatian siswa dan membuat siswa termotivasi serta fokus dalam belajar kosakata. Media flashcard dianggap sebagai suatu media yang menimbulkan kesenangan dan ketertarikan siswa dalam pembelajaran kosakata, karena flashcard dapat disajikan dalam bentuk permainan (Hotimah, 2010).

Penggalian informasi Mengenai Sub Topik Tentang Anemia ditampilkan pada gambar 1

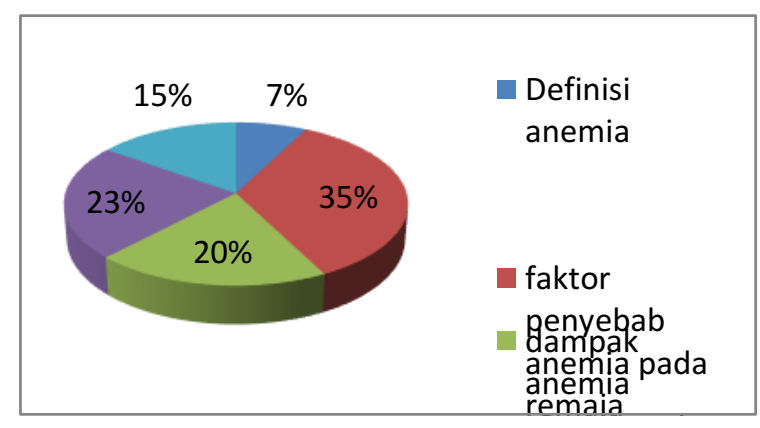

Gambar 1. Analisis Kebutuhan Materi pada Media

Informasi terkait sub topik
tentang anemia diperoleh melalui
kuesioner dimana beberapa siswi memilih lebih dari satu pilihan jawaban, analisis kebutuhan isi media pembelajaran flashcard tentang anemia merupakan gambaran isi materi yang akan dimasukkan dalam media pembelajaran. Hasil dari desain media flashcard menggunakan aplikasi photoshop Cs3. Isi Media flashcard hasil penelitian ditampilkan pada gambar 2 .

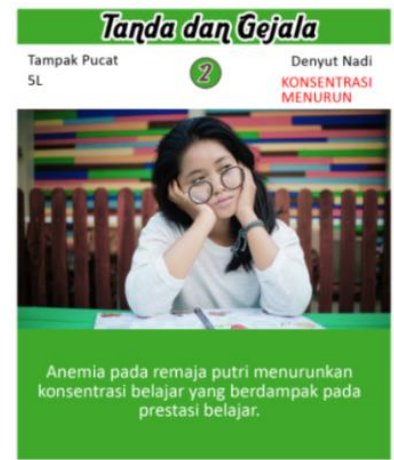

Gambar 2. Kartu Flascard

Bentuk media flashcard yaitu kotak berupa kartu pembelajaran. Kartu tersebut berisi gambar dan materi mengenai anemia. Tulisan yang terdapat pada cover antara lain adalah judul isi materi, subbab judul, penjelasan materi sesuai dengan judul, ada nomor di bagian tengah, materi tersebut disajikan kedalam lembar kartu dengan ukuran $8 \times 12 \mathrm{~cm}$. Bagian belakang kartu berisi tentang informasi kesehatan yang dapat dipelajari secara mandiri. Bagian belakang flashcard hasil penelitian ditampilkan pada gambar 3 berikut. 


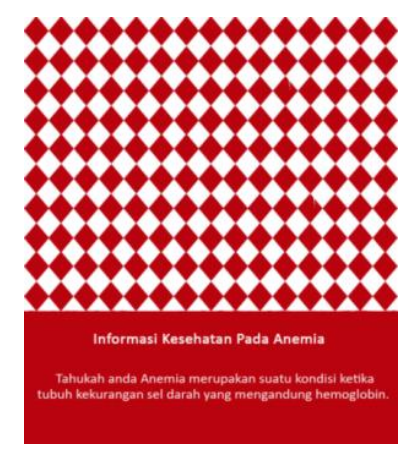

Gambar 3. Kartu flashcard Tampak Belakang

Kotak kartu berbentuk kubus dengan berisikan gambar, nama penyusun, serta logo. Desain kotak kartu flashcard ditampikan pada gambar 4

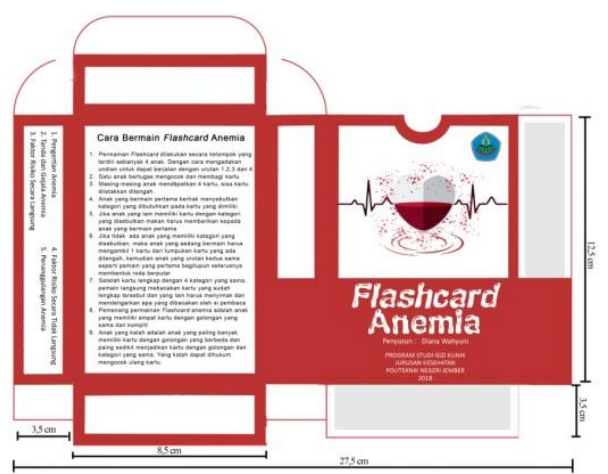

Gambar 4. Kotak kartu Media flahscard

Tahap yang dilakukan setelah media tercetak adalah melakukan uji coba produk pada subjek sasaran dengan menggunakan metode FGD (Focus Group Disscusion). Tujuan uji coba ini adalah mengetahui penialain subjek terhadap media dan memperoleh saran perbaikan. Jumlah siswi yang berperan pada dalam tahap ini sebanyak 10 orang. Menurut Sarwono (2006) metode FGD memerlukan beberapa orang yang biasanya terdiri dari $5-10$ orang. Hasil yang diperoleh dari metode diskusi ini berupa saran terkait media pembelajaran flashcard, dimana pada diskusi yang dilakukan oleh siswi dapat disimpulkan bahwa media pembelajaran flashcard memiliki bentuk yang menarik, warna kartu yang menarik karena tidak menyulitkan untuk membaca dan memahami gambar, isi materi yang mudah dipahami dan tulisan pada kartu jelas karena ukuran font yang digunakan sudah sesuai. untuk $\begin{gathered}\text { Selanjutnya dilakukan perbaikan } \\ \text { meningkatkan penerimaan }\end{gathered}$ flashcard. Perbaikan yang dilakukan pada kartu yaitu perubahan ukuran, hal ini dikarenakan terdapat beberapa siswi yang kesulitan pada saat memegang dan mengocok kartu sehingga memberikan saran untuk memperkecil ukuran agar mudah digenggam. Ukuran kartu sebelum direvisi adalah $20 \times 18 \mathrm{~cm}$ kemudian setelah dilakukan penyuntingan kembali ukuran kartu berubah menjadi $8 \times 12 \mathrm{~cm}$. Latar belakang direvisi dengan mengganti border yang simple dan praktis. Judul subbab diperbaiki dengan memperbesar ukuran font sehingga terlihat lebih jelas dan tidak kontras antara judul subbab dan judul sub subbab. Gambar pada kartu media flashcard direvisi agar warnanya kontras dengan background sehingga bisa membedakan antara gambar dan background.

Tahap selanjutnya adalah melakukan validasi media menggunakan medote FGD terhadap ahli materi dan ahli media. Validator media merupakan akademisi dari Politeknik Negeri Jember, sedangkan validator materi adalah akademisi dari Politeknik Negeri Jember, guru SMA Muhammadiyah 3 Jember dan ahli gizi Rumah Sakit Citra Husada yang berkompeten dalam materi gizi khususnya anemia remaja Validator memberikan beberapa saran perbaikan terkait materi dan media, seperti penambahan menu topik tentang anemia. Saran perbaikan untuk isi flashcard yaitu penjelasan yang lebih rinci mengenai singkatan kata yang asing dengan menggunakan huruf miring dan huruf kapital, sedangkan pada gambar disarankan menggunakan gambar yang memiliki sumber yang jelas untuk menghindari adanya klaim dari pihak lain. Revisi produk pada media flashcard dilakukan setelah evaluasi oleh ahli materi dan ahli media.

Aspek penilaian yang divalidasi oleh Ahli Media antara lain kesesuaian warna judul dengan background, ukuran kertas cetak, ukuran dan tipe huruf, penggunaaan huruf jelas, kesesuaian 
warna huruf dengan background, pemilihan warna sesuai karakter, pemilihan warna, kualitas gambar, layout gambar rapi, gambar membantu memahami dan kualitas media. Seluruh aspek penilaian dirata-rata dan skor akhirnya adalah $92,72 \%$ yang masuk dalam kategori "layak".

Aspek penilaian yang divalidasi oleh Ahli materi antara lain antara lain isi yang sesuai kebutuhan, mudah dipahami, sesuai dengan konsep, cakupan materi sesuai dengan karakteristik siswa, penyampaian yang menarik, penyampaian runtut dan materi dapat digunakan pada kelompok kecil dan kelompok besar. Dari hasil rata-rata aspek penilaian maka didapatkan skor 97,5\% dan masuk dalam kategori "layak

Data hasil penilaian flashcard kepada siswa, disajikan dalam gambar 5.

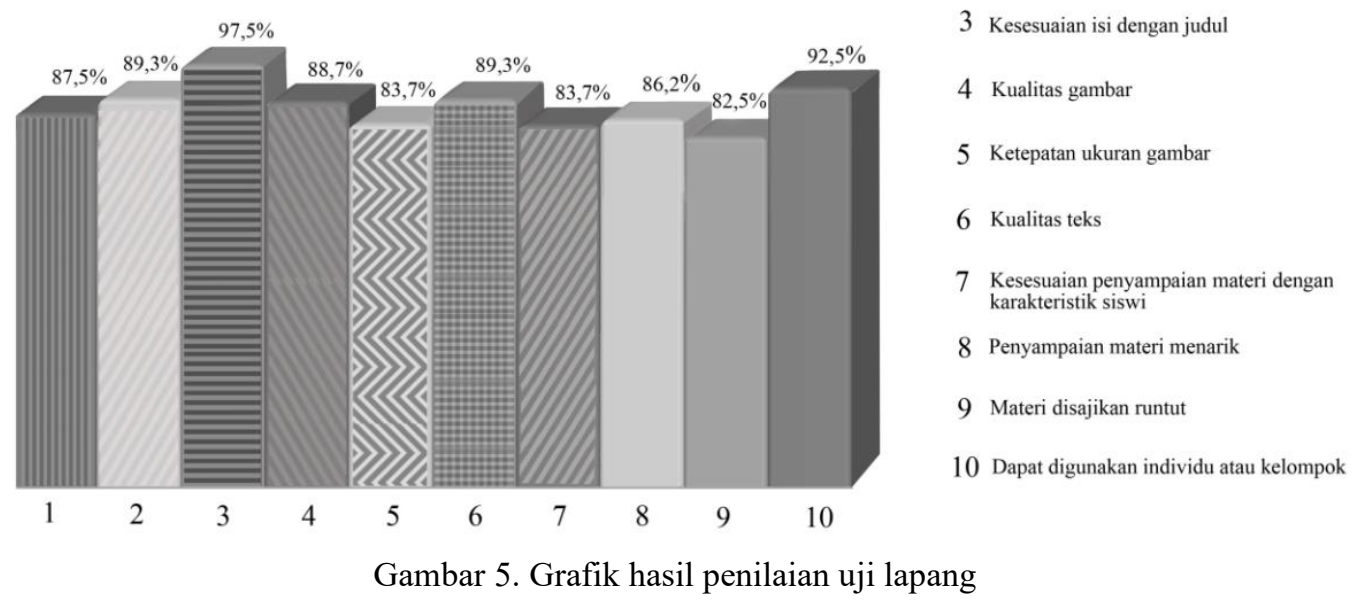

Berdasarkan grafik 4.11 di atas, dapat diketahui bahwa hasil penilaian siswi pada uji lapang terhadap media flashcard termasuk dalam kriteria "sangat baik" dalam aspek pengguna dengan nilai rata-rata $88 \%$. Ketuntasan pembelajaran dengan menggunakan media adalah $80 \%$ siswa yang mengikuti pembelajaran mampu mencapai tingkat penguasaan materi minimal $80 \%$ siswa yang mengikuti pembelajaran mencapai skor 75 (skor maksimal adalah 100) (Yamasari, 2010). Hasil penelitian menunjukkan bahwa 91,9\% hasil belajar siswa telah mencapai tingkat penguasaan materi dan memenuhi ketuntasan belajar atau dengan kata lain $\geq 80 \%$ dari 37 orang siswa telah mencapai nilai 75 , maka dapat dikatakan bahwa media pembelajaran ini telah efektif.

\section{Simpulan dan Saran \\ 4.1. Simpulan}

Telah dihasilkan flashcard anemia yang dikembangkan dengan metode Borg \& Gall dan dilakukan validasi media dan validasi materi sehingga dapat dikatakan media pembelajaran tersebut termasuk dalam kategori "layak". Hasil uji lapang menunjukkan bahwa hasil penilaian siswi terhadap media flashcard termasuk dalam kriteria "sangat baik" dalam aspek pengguna dengan nilai rata-rata $88 \%$. Hasil belajar siswa menunjukkan $91,9 \%$ siswa telah mencapai tingkat penguasaan materi dan memenuhi ketuntasan belajar.

\subsection{Saran}

Saran yang diberikan pada penelitian ini adalah perlu adanya program penanggulangan anemia remaja, dengan memanfaatkan berbagai media edukasi salah satunya flashcard 
anemia. Perlu adanya penelitian lanjutan terkait efektifitas media flashcard anemia yang telah dikembangkan ini.

\section{Daftar Pustaka}

Brown, H.D. (2008). Prinsip Pembelajaran dan Pengajaran Bahasa, edisi kelima, Kedutaan Besar Amerika Serikat di Jakarta

Hotimah, E. (2010). Penggunaan Media Flashcard dalam Meningkatkan Kemampuan Siswa pada Pembelajaran Kosakata Bahasa Inggris Kelas II MI Ar-Rochman Samarang Garut. Jurnal Pendidikan. 4(1). Sitasi 14 Februari 2018

Kementrian Kesehatan Republik Indonesia. (2007). Laporan Hasil Riset Kesehatan Dasar. Jakarta: Badan Penelitian dan Pengembangan Kesehatan Kemenkes RI

(2013). Laporan Hasil Riset Kesehatan Dasar. Jakarta: Badan Penelitian dan Pengembangan Kesehatan Kemenkes RI

Tegeh, I. M., Jampel, I. N., \& Pudjawan, K. (2014). Model penelitian pengembangan. Yogyakarta: Graha Ilmu.

Nugroho, Y.S., Nurkamto, J., and Sulistyowati, H. (2012). Improving Students' Vocabulary Mastery Using Flash Cards, English Education Journal, 1(1).

Susilana, R., Riyana, C. (2009). Media pembelajaran. Bandung: $\mathrm{CV}$ Wacana Prima.

Sugiyono. (2012). Metode Penelitian Kuantitatif, Kualitatif, dan $R \& D$. Bandung: Alfabeta

Sarwono, S.W. (2006). Psikologi Remaja. Jakarta: PT. Raja Grafindo Persada.

World Health Organization. (2011). The Global Prevalence Of Anemia In 2011. Geneva: World Health Organization

Yamasari, Y. (2010). Pengembangan Media Pembelajaran Matematika Berbasis ICT Yang Berkualitas. Seminar Nasional Pasca sarjana $X-I T S$, Surabaya 4 Agustus 2010 ISBN No. 979-545-0270-1 